

\title{
Fluoride: Double-Edged Sword Implicated in Caries Pre- vention and in Fluorosis
}

\section{Michel Goldberg}

\section{Faculté des Sciences Fondamentales et Biomédicales Cellules Souches, Signalisation et Prions, University Paris Descartes, France}

\begin{abstract}
How fluoride acts to prevent caries as well as cause demineralization is not well understood. Tunnels located inside apatite crystals are acting as ions exchangers favoring diffusion pathways, and substitution of ions such as fluoride inside the crystal lattice. Cariostatique effects prevent the carious decay, increasing the mineral solubility and remineralization. Given systemically or topically, fluorides added to water or used as salt, varnish, gel or paste, decrease the number and severity of carious lesions on deciduous and/or permanent erupted teeth. It comes out from fluoride supplementation that dental fluorosis may be induced. Slight fluorosis appears as white spots resulting from enamel hypomineralization. Pitting forming horizontal lines running across the surface of the teeth was also seen. For high doses of fluoride, altered enamel surfaces merge into large pigmented (brown to black) defects. Hence, fluorides appear as a double sword, actually involved in caries prevention, but also inducing mild to severe enamel deficiencies. Equilibrium between the well-documented caries prevention and fluoride contribution to enamel pathology implies a daily intake evaluation. The needs for fluoride consumption have to be carefully identified. They should be evaluated according to the age of the patient, the frequency of ingestion, and the mode of absorption.
\end{abstract}

\section{Fluorides in Dental Tissues: Organization, Substitutions, and Apatite-Type Structures of the Mineral Phase}

\section{Dental enamel}

Dental enamel comprised $96 \%$ mineral (by volume), similar to Hydroxyapatite (HAp) $\left(\mathrm{Ca}_{10}\left(\mathrm{PO}_{4}\right)_{6}(\mathrm{OH})_{2}\right)$, free (1\%) and bound (2.6\%) water (for a total of 3.6\%), and organic components $0.4-0.6 \%$, including proteins and lipids $[1,2]$. Replacement of calcium ions by substitution in the crystal lattice is occurring for carbonate and other ions. Fluorides are associated with such regulation, or they are substituted for hydroxyl ions. The spaces between the prisms and crystallites are filled with water and organic material, forming diffusion pathways for acids, mineral components including fluoride ions, and organic material. Tunnels are in evidence, acting as ions exchangers. Fluoride substitutions in the crystalline lattice induce very feeble variations of the crystallographic network, gains in measurements indicating variations between a few millimeters and a small number of hundred angstroms.

Between 2 to $5 \%$ of enamel mineral is recognized to contain carbonate, changing the dimensions of the unit cell of the crystal, and consequently the solubility of the apatite [3-6]. The phosphates containing $\mathrm{HPO}_{4}^{2-}$ and $\mathrm{PO}_{4}^{3-}$ generally constitute the biologically relevant calcium phosphate of dental tissues. The solubility behavior of hydroxyapatite at various levels of fluoride substitution revealed that the maximum effect was obtained when $50 \%$ of the hydroxyl groups had been replaced, corresponding to the greatest lattice stability and reflecting a low lattice free energy. Two different types of heterogeneous fluoridated hydroxyapatites were synthetized. They look either as HAp covered with fluoroapatite, or as fluoroapatite covered with hydroxyapatite (H-Ap and F-Ap) [7].

By definition, all calcium orthophosphates consist of three major chemical elements, calcium, phosphorus,

*Corresponding author: Michel Goldberg, Faculté des Sciences Fondamentales et Biomédicales Cellules Souches, Signalisation et Prions, University Paris Descartes, Sorbonne, Paris Cité, 75006 Paris, France, Tel: 33-1-42-86-3851; 33-1-6-62-67-67-09, E-mail: mgoldod@gmail.com

Received: April 26, 2017: Accepted: February 26, 2018: Published online: February 28, 2018

Citation: Goldberg M (2018) Fluoride: Double-Edged Sword Implicated in Caries Prevention and in Fluorosis. J Cell Dev Biol 1(1):10-22

Copyright: @ 2018 Goldberg M. This is an open-access article distributed under the terms of the Creative Commons Attribution License, which permits unrestricted use, distribution, and reproduction in any medium, provided the original author and source are credited. 
and oxygen, as parts of orthophosphate anions. The apatite family includes three main structural types:

1. The apatite type, which includes the derivatives of hydroxyapatite and fluoroapatite, as well as those related to apatite-type structures such as Octacalcium Phosphate (OCP);

2. The glaserite type, including all polymorphs of tricalcium phosphates;

3. The $\mathrm{Ca}-\mathrm{Po}_{4}$ sheet-containing compounds, including dicalcium phosphate dihydrate, dicalcium phosphate anhydrous and monocalcium phosphates. Amorphous Calcium Phosphate (ACP), a possible precursor to bioapatite, may be related to one or more of the structural types reported above.

Hydroxyapatite (OHAp, $\left.\mathrm{Ca}_{10}\left(\mathrm{PO}_{4}\right)_{6}(\mathrm{OH})_{2}\right)$, chlorapatite, carbonated apatites and Fluoroapatite (FAp, $\mathrm{Ca}_{10}\left(\mathrm{PO}_{4}\right)_{6} \mathrm{~F}_{2}$ and other calcium apatites are important in biology because they form the mineral part of bone and teeth. They take part in the mineralization process, and prevent caries. Fluorides increase the resistance of the mineral to acid dissolution, and decrease the mineral solubility $[8,9]$.

The most well documented effect of fluoride is ion substitutes for a column hydroxyl in the apatite structure. This is giving rise to a reduction of crystal volume and a concomitant increase in structural stability. In the process of enamel mineralization during amelogenesis, free fluoride ions in the fluid phase are supposed to accelerate the hydrolysis of acidic precursor(s) and increa-

Table 1: Range of therapeutic fluoride concentrations used to prevent caries [30,31].

\begin{tabular}{|l|l|}
\hline Method/vehicle & $\begin{array}{l}\text { Fluoride } \\
\text { concentration } \\
\text { (ppm F) }\end{array}$ \\
\hline Water supplies & $0.7-1.2$ \\
\hline Fluoridated salt & $200-250$ \\
\hline Mouth rinse, daily & 230 \\
\hline Dentifrices, children & $250-500$ \\
\hline Mouth rinse, weekly & 920 \\
\hline Dentifrices, adult & $1,000-1,500$ \\
\hline Self-applied gels or rinses, prescription & 5,000 \\
\hline Professionally applied solutions (NaF) & 9,200 \\
\hline $\begin{array}{l}\text { Professionally applied solutions, gels, } \\
\text { foams (APF) }\end{array}$ & 12,300 \\
\hline Professionally applied solutions (SnF2) & 19,500 \\
\hline Professionally applied varnishes & 22,600 \\
\hline
\end{tabular}

se the driving force for the growth of apatitic mineral. The substitution of fluoride in the hydroxyapatite occurs during the crystal development with carbonate, and magnesium.

Fluoride improves the quality of mineralized tooth tissues in general, by reducing the relative amounts of carbonated apatite. The reaction between hydroxyapatite and low concentrations of fluoride has been postulated to be an ionic exchange, in which fluoride replaces and assumes the positions of the hydroxyl ions in the crystal lattice structure. The replacement of hydroxyl groups with the smaller fluoride ions results in a more stable apatitic structure. If the $\mathrm{OH}^{-}$ion in the pure hydroxyapatite is completely replaced by a fluoride ion $\left(\mathrm{F}^{-}\right)$the resulting mineral is a fluoroapatite $\left[\mathrm{Ca}_{10}\left(\mathrm{PO}_{4}\right)_{6} \mathrm{~F}_{2}\right]$. However, pure fluoroapatite can practically never be found. Only $10 \%$ of the hydroxyl groups can be substituted by fluoride in the surface enamel $[2,6]$.

Three main forms of fluoride ion have been identified with respect to their reactivity in the presence of apatite:

1. Iso-ionic exchange off- for $\mathrm{OH}^{-}$in apatite: $\mathrm{Ca}_{10}\left(\mathrm{PO}_{4}\right)_{6}(\mathrm{OH})_{2}$ $+2 \mathrm{~F}^{-} \rightarrow \mathrm{Ca}_{10}\left(\mathrm{PO}_{4}\right)_{6} \mathrm{~F}_{2}+2 \mathrm{OH}^{-}$

2. Crystal growth of fluoroapatite from supersaturated solutions: $10 \mathrm{Ca}^{2+}+6 \mathrm{PO}_{4}^{3-}+2 \mathrm{~F}^{-} \rightarrow \mathrm{Ca}_{10}\left(\mathrm{PO}_{4}\right)_{6} \mathrm{~F}_{2}$

3. Apatite dissolution with $\mathrm{CaF}_{2}$ formation: $\mathrm{Ca}_{10}\left(\mathrm{PO}_{4}\right)_{6}(\mathrm{OH})_{2}+20 \mathrm{~F}^{-} \rightarrow 10 \mathrm{CaF} 2+6 \mathrm{PO}_{4}^{3-}+2 \mathrm{OH}$

The first two reactions may occur during long-term exposure to low fluoride levels in the solution (such as between 0.01 and $10 \mathrm{ppm}$ F) from either systemic or latent topical sources. These reactions result in fluoride incorporation that would be defined as "firmly" bound fluoride, since it is part of the apatitic structure. This fluoride present in the solid phase is also known as fluorohydroxyapatite or "systemic" fluoride. With the increasing fluoride concentration, an additional chemical reaction with the formation of significant amounts of calcium fluoride $\left(\mathrm{CaF}_{2}\right.$ or " $\mathrm{CaF}_{2}$ - like" material) begins to dominate. Fluoride concentrations ranging from 100$10,000 \mathrm{ppm} F$ are required to produce $\mathrm{CaF}_{2}$ as a reaction product. These concentrations are present in topical applications, such as professional gels and varnishes, or over the counter toothpastes and mouth rinses.

The cariostatique effect of fluoride was attributed to the incorporation of fluoride in the hydroxyapatite cry-

Table 2: Comparative effectiveness of professionally applied topical fluoride agents.

\begin{tabular}{|l|l|l|}
\hline Agent & Fluoride concentration (ppm F) & Average effectiveness \% caries reduction \\
\hline $2 \% \mathrm{NaF}$ & 9,200 & 29 \\
\hline APF $(1.2 \% \mathrm{~F})$ & 12,300 & 22 \\
\hline $8 \% \mathrm{SnF} 2$ & 19,500 & 32 \\
\hline Fluoride varnish $(5 \% \mathrm{NaF})$ & 22,600 & 38 \\
\hline
\end{tabular}


stal lattice and the reduced solubility of the so-formed fluoridated hydroxyapatite. The current evidence from clinical and laboratory studies suggest that the cariespreventive mode of action of fluoride is mainly topical. Specifically, fluoride continually present in the oral fluids affects the demineralization and remineralisation processes. Fluoride present in the solution surrounding the crystals (enamel fluid) in a sub-ppm range is able to adsorb to the surface of the carbonated apatite crystals, inhibiting demineralization [10].

Once fluoride is incorporated into the enamel mineral, the ion affects the subsequent mineralization process by reducing the solubility of the mineral and by modulating the ionic composition in the fluid surrounding the mineral. It enhances the matrix protein-mineral interaction, but excess fluoride leads to anomalous enamel formation by retarding tissue maturation.

The weight per cent (including constitutional water) and density of the enamel apatite crystals for the most probable model are about $98 \mathrm{wt} . \%$ and $3.0 \mathrm{~g} \mathrm{~cm}^{-3}$, respectively. Calculated from these values, the apatite volume is about $96 \%$. The weight and volume percent of enamel apatite are higher than normally accepted values because of inclusion of constitutional water. The density for enamel apatite takes into account its known lattice expansion over hydroxyapatite and lattice vacancies.

Apatite type structures: Apatites are known to accommodate modifications and combinations of substitutions of ions and groups within the apatitic lattice. However, the term "apatite" has been extensively and synonymously used to represent the calcium phosphates. Apatites are thermodynamically the most stable phases among the calcium phosphates and, therefore, can be considered as the probable end product in many reactions.

The most common form of hydroxyapatite is hexagonal and the crystal structure has been described in the space group $\mathrm{P} 63 / \mathrm{m}$ with lattice parameters $\mathrm{a}=\mathrm{b}=9.432$ $\AA$ and $\mathrm{c}=6.881 \AA, \mathrm{Z}=1$. Stoichiometric OHAp has been described as monoclinic, space group P 21/b having cell parameters $\mathrm{a}=9.4214 \AA, \mathrm{b}=2 \mathrm{a}, \mathrm{c}=6.8814 \AA,=120^{\circ}, \gamma$ with twice as many formula units per unit cell as in the hexagonal unit. Fluoroapatite is the most stable among the apatites. FAp is hexagonal with the space group $\mathrm{P}$ $63 / \mathrm{m}$ and lattice parameters, $\mathrm{a}=\mathrm{b}=9.367 \AA$ and $\mathrm{c}=$ $6.884 \AA, \mathrm{Z}=1$. Chloroapatite has been described in the hexagonal space group $P 63 / \mathrm{m}$, with cell parameters, a $=\mathrm{b}=9.598(2) \AA, \mathrm{c}=6.776(4) \AA, \mathrm{Z}=1$. Substituted apatites: OHAp can incorporate a wide variety of substitutions for $\mathrm{Ca}^{2+}, \mathrm{PO}_{4}^{3-}$, and $\mathrm{OH}^{-}$ions. Biological apatites are rarely stoichiometric. They are usually calcium-deficient, and contain a wide variety of relatively small amounts of other substituent atoms or groups. Carbonate apatites: There are two generally accepted locations for the $\mathrm{CO}_{3}{ }^{2-}$ ion in the apatite lattice: One on the head axis at the $\mathrm{OH}^{-}$ion site (type- $\mathrm{A}$ ) and the other for $\mathrm{PO}_{4}^{3-}$ (typeB). Type-B substitution would require involvement of additional ions. Biological apatites are principally typeB carbonates, with small amount of type-A. However, the structure of carbonate-apatite remains controversial. Octacalcium Phosphate (OCP): The crystals are triclinic. Cells parameters $\mathrm{a}=19.692 \AA, \mathrm{b}=9.523 \AA, \mathrm{c}=6.835 \AA$, and $Z=2$. The structure of OCP has been described in terms of alternating apatitic and hydrated layers parallel to the (100) face. Closer examination of the structure reveals that the "hydrated layer" is only a hydrated region or a channel along the $\mathrm{c}$-axis at the center of the unit cell, since the apatitic layers are held together by strong bonds involving the $\mathrm{Ca}^{3}, \mathrm{Ca}^{4}$, and the $\mathrm{HPO}_{4}^{2-}$ groups along the a-axis. The structure of OCP has been described in terms of alternating apatitic and hydrated layers parallel to the (100) face. Regardless of the amount of water, this region provides an open channel along the c-axis for the transport of $\mathrm{Ca}^{2+}$ or other ions that can be incorporated into the resulting apatitic products during the transformation or hydrolysis of OCP. Tetracalcium Phosphates (TCP), tricalcium phosphates, and glaserite-type structures are members of the same family [8].

Interactions between fluoride and dental enamel are primarily active by lowering the solubility of the apatitic mineral phase of dental hard tissues. Fluoride present in the oral fluids alters the rate of naturally occurring dissolution and reprecipitation processes. During tooth dissolution, chemical changes occur. The solubility of enamel powder increases dramatically with a decrease of $\mathrm{pH}$. A high concentration of fluoride in solution leads to low enamel dissolution. Occurring only in the solid phase, the solubility is only slightly affected. The enamel surface layer accumulating fluoride remains relatively intact, while the sub-surface enamel dissolves $[4,8,9]$.

Demineralization is inhibited by concentrations of fluoride in the sub-ppm range. Remineralization of incipient carious lesions is accelerated by trace amount of fluoride. The balance between de- and re-mineralization is favorably shifted by fluoride. It has been postulated that in the presence of fluoride ions the percentage of lattice surfaces participating in the crystal growth is increased, due to the greater thermodynamic driving force for precipitation; not only the most reactive surfaces, but also the whole crystal contributes to this increase. In conclusion, apatite precipitation was enhanced through the formation of Fluoroapatite (FAP).

There is an observed inhibitory effect of fluoride on remineralization to the above mentioned effects of fluoride on crystal growth. The remaining porosity of the 
surface layer is sufficient to allow mass transfer to the deeper regions.

When fluoride is added to acidified buffers in order to induce an artificial enamel lesion, two phenomena are observed. First the rate of lesion formation is slowed down, and second fluoride has an effect on the histologic appearance of the lesions that develop. At calcium and phosphate concentrations in the demineralizing solution, significant inhibition was observed with solution fluoride concentrations of 0.2 to $2 \mathrm{ppm}$ fluoride, for $\mathrm{pH} 5.0$ to 4.0 , respectively, in solutions less undersaturated with HAP (11.7 mmol/l Ca, $6.0 \mathrm{mmol} / \mathrm{I} \mathrm{PO}_{4}$ at $\mathrm{pH}=4.3$ ) [9].

\section{Dentin composition}

Compared to enamel composition, the mineral phase (apatite) decreases down to $70 \%$. The water increases up to $10-12 \%$ and organic components account for $20 \%$. The dentin crystallites have much smaller dimensions, compared to enamel crystallites. Carbonate, magnesium, sodium, potassium, chloride, fluoride, potassium, sulfur, copper, silica, iron, and zinc are all included in the mineral phase. The following weight and molar ratio for enamel and dentin are Ca:P (weight) 2.08/2.07, and molar for both are 1.64. The network of HAp forms a hexagonal mesh, parallel to the c-axis, leaving, as it is the case for enamel, open tunnels. The diameter of the tunnel varies between 3 and $3.5 \AA[11,12]$. They may contribute to substitutions in the apatitic network. Cation such as $\mathrm{Ca}^{2+}$ may be partially or totally substituted by $\mathrm{Sr}^{2+}, \mathrm{Ba}^{2+}, \mathrm{Pb}^{2+}$, or $\mathrm{Mg}^{2+}$. Anions of the $\mathrm{PO}_{4}^{3-}$-type may be replaced by ions bearing the same charge $\left(\mathrm{AsO}_{4}{ }^{3-}, \mathrm{VO}_{4}{ }^{3-}\right) . \mathrm{OH}^{-}$may be substituted by anions. This is the case for $\mathrm{F}^{-}, \mathrm{Cl}^{-}$, and $\mathrm{Br}^{-}$. Tunnels permit either anions or cations exchanges, or they allow the addition of ions to the crystal structure, and/or to the hydroxyapatite network.

Fluoride participates in many aspects to calcium phosphate formation in vivo and has enormous effects on the process, nature and properties of the formed mineral. A well-documented effect of fluoride is that $\mathrm{F}^{-}$constitutes a valid substitute for a column hydroxyl in the apatite structure. It gives rise to a reduction of crystal volume and to a concomitant increase in crystal stability. Fluoride participates in many aspects to calcium phosphate formation in vivo. It has an enormous effects on the process, nature, and properties of the formed mineral. Excesses of fluoride lead to anomalous apatite growth on the seeded surfaces. Progresses are observed in two discrete manners: (1) Crystal elongation along the c-axis is initiated by deposition of small protrusions on the basal plane, and (2) The growth reaction on the side prism planes is characterized by the advancement of growth. These steps are corresponding to one or a few unit-cell thickness [3].
Intertubular dentin, peritubular dentin, and intraluminal mineralizations constitute dentin compartments, which react differently to the carious decay. Tiny crystals, $70 \mathrm{~nm}$ in length, $10 \mathrm{~nm}$ thick are present along and between collagen fibrils in the intertubular dentin. Isodiametric crystals load the homogeneous peritubular dentin. The lumen of the tubules is partially or totally closed by $100 \mathrm{~nm}$ long needle-like crystals, which looks very similar to apatitic crystals, whitlockite and/or amorphous calcium phosphate. Apatitic-like re-precipitations and occluded tubules containing various forms of calcium phosphate are especially numerous in the sclerotic zone. Beneath this layer, dentin looks "normal" and in the pulp reactionary dentin and pulp stones are seen [10].

\section{Dental Caries}

Dental caries have a prevalence of $40 \%$ at the age of 7 years, and $85 \%$ in seventeen-year-old boys [11]. During the last decades caries has firmly decreased. About 50\% of the children are caries-free in permanent dentition. Therefore proofs of efficacy of medical and non-medical treatments on prevention of caries rise from epidemiologic studies. A strong link was established between the carious lesions and fluoridation. Fluoride varnish, gels or paste, or mouth rinses were recommended. They improved the prevention of caries from $23 \%$ to $36 \%$ seen in populations compared to placebo.

Caries is a transmissible bacterial disease caused by acids issued from bacterial metabolism and diffusing into enamel and dentin. The mineral phase is dissolved by lactic, acetic, formic and propionic acids, all of which contribute to the demineralization of the mineral phase of dental tissues. Caries comprises two "independent" processes: (1) Demineralization of enamel after acid formation by the bacterial plaque and (2) A natural repair of acid-produced enamel defects from plaque fluid or saliva at a $\mathrm{pH}$ near neutrality (remineralization). Intercrystallite spaces are filled with water and organic material, forming the diffusion pathway for acids, mineral components, and fluoride ions. Below the surface layer, there is a mineral loss, up to $50 \%$ vol before cavitation occurs $[9,13]$. At the crystal level, small calcium deficient and/or defective areas have expanded into hexagonal shaped regions where mineral has dissolved during acid attack. This is the first stage of demineralization, which is occurring at the atomic level, far before it can be detected visually as flagrant demineralization. This is the first step in the continuum of the dental caries process that can eventually lead to the formation of cavity. The strongly adsorbed, highly electronegative fluoride ion can protect, at least partially, against demineralization by acid, as revealed by dissolution studies.

The main mineral exchanges occur between crystals 
located at the surface of the tooth and the surrounding environment. Demineralization (mineral loss) occurs gradually, followed by mineral gain (remineralization).

Amelogenin and needle-like fluoridated hydroxyapatite crystals modulate the deposition of mineral on etched enamel, in an attempt to form a well mineralized surface $\mathrm{g} / \mathrm{mL}$ the $\mu$ layer. In the presence of $1 \mathrm{mg} /$ $\mathrm{mL}$ and at a minimal concentration of 33 formation of crystals growing at the enamel surface was initiated in a dose-dependent manner. Amelogenins promote the formation of oriented bundles of needle-like fluoridated hydroxyapatite nanocomposites. This novel material leads to future applications in reparative and restorative dentistry $[14,15]$.

\section{Control of caries}

It is well documented that fluoride prevents a significant percentage of new lesions, and therefore contribute to the control of the disease. Early lesions may be detected and remineralization arrests the unfavorable evolution of the disease. The aim of minimally invasive dentistry is to treat the initial (precocious) lesion, center in gnumerous therapies on remineralizing treatments to ensure that caries activity is arrested. Hidden occlusal lesions, imaging and modern detection methods allow to treat non-cavitated lesions. Acidogenic and acid-tolerant gram-positive bacteria such as streptococci mutans and lactobacilli and other bacteria species that are acid-sensitive are associated with sound enamel. Remineralization of tooth surfaces, which have already started to be demineralized but did not develop a cavity, constitutes a preliminary approach [16].

Topical fluoride ions, in the presence of calcium and phosphate ions, promote the formation of fluoroapatite in tooth enamel by a process referred to as remineralization. The non-invasive treatment of early caries lesions by remineralization has the potential to be a major advance in the clinical management of the disease [17]. Fluoride ions promote the formation of fluoroapatite in the presence of calcium and phosphate ions produced during enamel demineralization by the organic acids of the bacterial plaque. Insoluble calcium phosphates are not easily applied. They do not localize effectively at the tooth surface and require acids to produce ions capable of diffusing into enamel subsurface lesions.

Caries is a disease caused by a group of oral streptococcal microorganisms, comprised primarily of $S$. $m u$ tans that occurs in three phases:

1) Initial interaction with the tooth surface mediated by adhesins;

2) Accumulation of the bacteria in a biofilm and the production of glucose and glucans by the bacterial enzyme glucosyl transferase;
3) The formation of lactic, pyruvic, acetic, propionic and butyric acids that excerpt noxious effects (demineralization) on enamel surfaces $[10,13]$.

The strategy for prevention involves fluoride tooth paste, reducing the caries increment in the permanent DMFS (decayed, missing, and filled tooth surfaces) or primary $(\mathrm{dmfs} / \mathrm{t})$ dentition as endpoint. The results of systematic reviews revealed (from 1 to 4 )

1. Strong evidence in young permanent teeth that the daily use (two times a day or even once daily) of fluoride toothpaste was efficient compared to placebo.

2. Toothpastes with $1,500 \mathrm{ppm}$ of fluoride have a superior preventive effect compared with standard dentifrice with $1,000 \mathrm{ppm} \mathrm{F}$.

3. Higher caries reduction were recorded in studies with supervised tooth brushing compared with non-supervised.

4. Incomplete evidence was found regarding the effect of Fluoride toothpaste in primary dentition (no statistically significant difference, related to areas where water $\mathrm{F}$ is naturally low) $[10,18,19]$.

Children using tooth brushing with fluoride containing toothpastes prevent $24 \%$ DMF. For adults the reduction was only $12.2 \%$. The combined effects of fluoridated water, fluoride mouth rinse, gels or varnishes prevented a fraction of $23 \%$ of carious lesions. Resin sealants produced a relative caries reduction of $33 \%$ in permanent teeth of 5 to 10 -years-old children. Antibacterial, antimicrobial varnish and bactericidal agents are efficient tools in our armamentarium. Caries vaccines have produce some promise, but were in conclusive and they are still under investigation. For low-risk patients, minimal fluoride exposure is indicated. For patients at moderate-risk and high-risk, antibacterial or bactericidal agents should be considered for individuals with high levels of $S$. mutans. It comes out that caries should be assessed periodically to adjust the treatment, either the high-risk level of the patients decrease, or there is a significant increase during the active treatment [18].

Due to reduced functional usage, erupted teeth tend to accumulate plaque showing a cariogenic potential. For this reason, the period from the tooth emergence in the oral cavity to the establishment of interproximal contact and full occlusion is the most critical for caries initiation. Analyses of clinical data indicate that maximum protection against caries is obtained when teeth erupt in an environment with low concentrations of ionic fluoride. The pre-eruptive effect of fluoride is of minor significance compared to the more significant post-eruptive effect. On the basis of clinical data on water fluoridation and post-eruptive fluoride administration, it is possib- 
le to conclude that regular addition of small quantities of fluoride to the oral environment reduces the caries progression rate by about $50 \%$. Pre-natal fluoride intake cannot be recommended because there is no scientific evidence to support the view that additional benefit would be obtained through fluoride supplementation to pregnant women [19].

Since 1945, fluorides are available through tablets, mouth rinses, and lacquers. They were added to dentifrices. Fluorides interact at the interface between the tooth and oral fluids. Where as dental enamel comprised $96 \mathrm{wt}$ $\%$ of mineral, many substitutions occur in the crystal lattice, without loosing the HAp identity. The replacement of calcium ions is due to sodium, zinc, and strontium. Carbonates may occupy the phosphate position in the lattice. Both carbonate (2 to $5 \%$ ) and fluoride are substituted to hydroxyl ions. The spaces between the pris$\mathrm{ms}$ and the crystallites are filled with water and organic material (proteins and lipids), and intercristalline spaces allow the diffusion pathway for acid and mineral components.

Two independent processes are recognized as initiators of the carious decay: (a) After acid formation in the plaque, demineralization occurs, and (b) A natural repair of acid-produced enamel defects is occurring at $\mathrm{pH}$ near neutrality. For many years the cariostatique effect of fluoride was attributed to the incorporation of fluoride in the HAp lattice, reducing the solubility of the fluoridated hydroxyapatite. Using $0.2 \mathrm{ppm} \mathrm{NaF}$ daily, resulted in inhibiting the carious lesion formation. The "surface softened" enamel was used as substrate. deposition of apatitic mineral from Mineralizing solutions diffusing inside enamel was increased by a fluoride concentration up to $4 \mathrm{ppm}$. Fluoride-enhanced deposition occurred on the surface layer. Porosities of the surface layer were sufficient to allow deposition and transfer from the surface to deeper inner regions.

The mechanisms leading to the formation of a surface layer implies firstly that the outer enamel accumulate fluoride with time, with a lower solubility than the underlying enamel. The second hypothesis is based on the accumulation of dissolution inhibitors during demineralization. Combined, the two hypothesis leads to the concept of calcium and/or phosphate ions precipitation. Laminations develop in white spot defects that form under conditions of alternating fluoride supply and cariogenic challenges.

A fluoride reservoir exposed in the intraoral cariogenic dental plaque suggests that part of the $\mathrm{CaF}_{2}$ is converted to $\mathrm{Ca}_{10}\left(\mathrm{PO}_{4}\right)_{6} \mathrm{~F}_{2}$. The migration of ions in the mouth is however limited. Fluoride is continuously present in the daily cycle of cariogenic demineralization and repair.
Replacement of fluoride by the hydroxyl ions would produce Fluoroapatite (FA) that has a lower solubility. However, analysis of surface layers of enamel show that the fluoride contents are far below the level expected for FA. It is relevant to ascertain that partial substitution of the fluoride by the hydroxyl group in HA affects its solubility.

The reduction of enamel solubility and protection against caries are connected. During early formation of carious lesions, the existence of an apparently intact surface zone was seen over the enamel white-spot lesion. The enamel surface is the first layer where the carious attack takes place. Measurements indicate larger enamel crystallites dimensions, compared with sound enamel. Fluorides at low levels are affecting clinical caries incidence. At higher concentration, the fluoride ions influence the plaque behavior. Growth of apatite crystallites may influence remineralization. The preferential acquisition of calcium by calcium-deficient apatite reverses early carious changes [20].

Two major groups of bacteria are essential to the disease process: The streptococci mutans and the lactobacilli species. Mutans streptococci include Streptococcus mutans and S. sobrinus. The lactobacilli species are producers of lactic acid. These bacteria are the primary causative agents of dental caries. The acids diffuse into the tooth and dissolve the carbonated hydroxyapatite mineral, a process also called demineralization. They are producing organic acid during metabolism of fermentable carbohydrates, including lactic, acetic, formic, and propionic acids. The carious process is a continuum resulting from many cycles of de- and remineralization. Bacteria are acidogenic. They are living in an acid environment. Enamel and dentin crystals are in the order of $40-70 \mathrm{~nm}$ and $10 \mathrm{~nm}$ in thickness, respectively. Remineralization is occurring in the sub-surface non-cavitated carious lesions. Demineralization follows the central dislocation (screw dislocation of Burger's vectors). It begins at the atomic level along the c-axis, and stops when the demineralization is arrested or the progress of the lesionis reversed (lattice defects at the surface of the crystal or edge dislocations) [21]. Calcium and phosphate ions assisted by fluoride rebuilt a new surface of existing crystal remnants in sub-surface lesions, remnants that remain after demineralization. The remineralized crystals are acid resistant, and they are less soluble than the original mineral. Cycles of demineralization and remineralization continue in the mouth as long as cariogenic bacteria, fermentable carbohydrates and saliva are present. Dental caries is first observed clinically as so-called "white spot" lesion. The body of the subsurface lesion may have lost as much as $50 \%$ of the original mineral content and is covered by an apparently intact surface layer, formed by 
remineralization. Fluoride inhibits enolase, an enzyme necessary for the bacteria to metabolize carbohydrates.

Fluoride in solution is produced by topical sources that enhance remineralization. It is speeding up the growth of a new surface on the partially demineralized crystal located in the partially demineralized subsurface crystals of the caries lesion. Prevention includes fluoride therapy by inhibiting demineralization and enhancing remineralization. Clinically, two different approaches can be used. Firstly, molecular probes may be exploited for the quantitative detection of cariogenic bacteria at chair side. Secondly, genetically engineered IgA may be used as inhibitors of recolonization by cariogenic bacteria $[13,22]$.

Studying low levels of fluoride in solution on in vitro demineralized enamel, and exposed to $0.1 \mathrm{M}$ lactate solutions at $\mathrm{pH} 4.3$ containing between 0.004 and $1 \mathrm{ppm}$ fluoride, rapid enamel demineralization is occurring. The same demineralizing solution containing as little as 0.024 and $0.054 \mathrm{ppm}$ fluoride. It induces a remarkable protection of the enamel surface, with a sub-surface demineralization. No mineral loss was detected when the demineralizing solution contained $1 \mathrm{ppm}$ fluoride. The results obtained were consistent with a proposed hypothesis that the net rate of enamel demineralization will be reduced in a demineralizing medium supersaturated with respect to less soluble fluoridated phases [23].

In adult, the role of systemic fluorides prevents caries among patients of all ages. However, this role appears to be limited and primarily has a topical effect. Cariostatique mechanisms are linked to the oral environment, excerpt effects on plaque colonization, composition and metabolic activities, on mouth rinses, and water fluoridation. The slow dissolution of calcium fluoride deposited in initial caries lesions has for consequence to maintain the fluoride concentration locally for longer period of time [24].

Cochrane reviews on the benefits/risks of fluoride toothpastes conclude that the caries-preventive effects of fluoride toothpastes of different concentrations increase with high fluoride concentration (> $1000 \mathrm{ppm})$. They provide also evidence that childless than 12 months of age display an increased risk of fluorosis. The decision concerning the fluoride levels in children less than 6 years should be balanced between the risk of developing caries and that of mild fluorosis [25].

Etiology and prevention of Early Childhood Caries (ECC) remains one of the most common chronic diseases of early childhood [26]. ECC appears to be a virulent form of dental caries, causing extensive rapid destruction of deciduous teeth. Other terms for such diseases are "baby bottle tooth decay" and/or "nursing caries".
Frequent consumption of sugar favors the establishment of cariogenic bacteria and provides continuous substrate that influences the initiation and progression of caries. Teeth become less susceptible to decay over time. The enamel matures, incorporating orally available ions including fluoride. Therefore, a tooth is more susceptible to caries immediately after eruption until final maturation.

The effect of fluoride on reducing caries is now well established. Fluoride may be delivered in two ways: Systematically and topically. Water fluoridation allows for both systemic and topical effects. Water ingested during development of the teeth allows fluoride to be incorporated into the developing dental tissues, making them more resistant to demineralization.

Six monthly applications of a $40 \%$ chlorhexidin varnish were effective, showing a $37.3 \%$ reduction in caries increment without side effects. This reduction was also close to that found in a meta-analysis regarding the effectiveness of fluoride varnish on caries prevention in primary teeth, with a $33 \%$ reduction [27]. It was concluded that fluoride varnish could also introduce the risk of the development of enamel fluorosis in the permanent teeth. The evidence of a major benefit from fluoride consumption during infancy is lacking, and thus, it seems reasonable to limit the intake of fluoride to less than $70 \mu \mathrm{g} /$ $\mathrm{kg}$ BW per day, considering the possible risk of enamel fluorosis. To avoid greater intake, water with relatively low fluoride content (e.g., 0-0.3 mg/L) is recommended to be used as a diluent for infant formula, and no fluoride supplement should be given to infants. Small children swallow the applied dentifrice. Education regarding appropriate tooth brushing in small children is needed for mothers. The recommended limit in the amount of dentifrice should be no more than $0.25 \mathrm{~g}$ per brushing [27].

In healthy human enamel, Fluorohydroxyapatite (FHAP) or Fluoroapatite (FAP) is given in addition to HAP in the outer most enamel layer. Less than $5 \%$ of the $\mathrm{OH}$ groups are replaced by fluoride. At a depth $\mathrm{m}$, the $\mu$ of 50 percentage drops further, enamel being a calciumdeficient, carbonate-rich hydroxyapatite.

Calcium fluoride prevents caries. In vitro, calcium fluoride is only formed at fluoride concentrations of at least $300 \mathrm{ppm}$ when solutions with a neutral $\mathrm{pH}$ are applied. In contrast, at $\mathrm{pH} 5$, a concentration of $100 \mathrm{ppm}$ fluoride is sufficient to initiate spontaneous precipitation of calcium fluoride. In this case, $\mathrm{CaF}$ appears at the mineralized surface as spherical globules.

Water fluoridation prevents about $27 \%$ of caries among adults of all ages. The proportion of the U.S. population comprised of older adults is increasing. Most of these persons are likely to be dentate and at risk for 
dental caries. Many lower-income adults lack access to timely restorative care. Fluoride is effective among all adults. The development and implementation of fluoride programs assist all the members of this population [28].

\section{Remineralization systems}

Topical fluoride ions, in the presence of calcium and phosphate ions, promote the formation of fluoroapatite in tooth enamel by a process referred to as remineralization. Fluoride ions promote the formation of fluoroapatite in enamel in the presence of calcium and phosphate ions produced during enamel demineralization by plaque bacterial organic acids. This may be the major mechanism of fluoride ion's action in preventing enamel demineralization. Fluoride can also determinate the remineralization of previously demineralized enamel if enough salivary or plaque calcium and phosphate ions is available when fluoride is applied. The non-invasive treatment of early caries lesions by remineralization is a major advance in the clinical management of the disease. However, for every two fluoride ions, 10 calcium ions and six phosphate ions are required to form one unit cell of fluoroapatite $\left(\mathrm{Ca}_{10}\left(\mathrm{PO}_{4}\right)_{6} \mathrm{~F}_{2}\right)$. Following topical application of fluoride ions, the availability of calcium and phosphate ions can be the limiting factor for enamel remineralization [17].

Fluoride therapy in the prevention of dental caries has been is developed in the form of varnish, gel, mouth rinse, and toothpaste. The decline of caries has been attributed to the cariostatique efficacy of fluoride. In 2006, the Center for Disease Control and Prevention (CDC), Environmental Protection Agency (EPA) and the American Dental Association (ADA) have recommended for the amount of drinking water to be $\mathrm{g} / \mathrm{ml} \mu 0.7$ (ppm). This could vary between $0.7 \mathrm{ppm}$ in warmer climate to 1.2 in cooler climates. Fluoride-containing products were introduced with extensive water, salt, and milk fluoridation. Gels, varnishes, rinses, and/or prophylaxis pastes may contribute to remineralization systems [29].

\section{Topical fluoride}

The panel of experts recommends topical fluoride agents only for people who are at elevated risk of developing dental caries. A 2.26\% fluoride varnish (for children younger than 6 years) or 1.23 percent fluoride gel (APF) for patients 6-years-old or older may contribute efficiently to caries prevention.

Different fluoride compounds, different vehicles, and concentrations have been used with different frequencies and durations of application. These variables influence the clinical outcome with respect to caries prevention and management. The efficacy of topical fluoride in caries prevention depends on a) The concentration of fluo- ride used, b) The frequency and duration of application, and, c) The specific fluoride compound used.

For non-cavitated smooth surface carious lesions in a moderate caries-risk patient, the appropriate fluoride regimen would be semiannual professional topical application of a fluoride varnish containing 5 percent $\mathrm{NaF}$ (22,600 ppm of fluoride). The patient should use daily for at least one minute a fluoridated dentifrice containing NaF, MFP, or SnF2 (1,000-1,500 ppm of fluoride), and once daily for one minute a fluoride mouthrinse containing NaF\% (230 ppm of fluoride). If the non-cavitated carious lesion involves a pit or fissure, the application of an occlusal sealant would be the most appropriate preventive therapy.

In order to avoid unintentional ingestion and the risk of fluorosis in children less than six years of age, fluoride rinses and gels should not be used at home. Furthermore, when using a fluoride dentifrice, children should apply only a pea-size portion on the brush, should be instructed not to eat or swallow the paste, and should expectorate thoroughly after brushing. Tooth brushing should be done under parental supervision [30].

\section{Enamel Fluorosis}

Enamel fluorosis is a developmental disturbance of dental enamel. Observed in young children at fluoride intakes as low as $0.03 \mathrm{mg} \mathrm{F} / \mathrm{kg}$ body weight, and there is a clear linear relationship between fluoride dose and the development of dental fluorosis, regardless of whether fluoride is ingested from drinking water, from supplements, or from other sources. The severity of dental fluorosis depends on when and how long the overexposure to fluoride occurs. The risk period in permanent teeth is between 20 and 30 months of age. The daily $\mathrm{F}$ dose intake is $0.05-0.07 \mathrm{mg} / \mathrm{F} / \mathrm{Kg} /$ day. It prevents dental caries, and is acting in remineralization. Opaque defects are detected at low doses. Higher dose leads to an obvious increase of dental fluorosis, hypomineralized enamel, pitting and larger non-pigmented and pigmented lesions.

Fluorosis occurs as a result of long-term intake of fluoride during the pre-eruptive development of teeth. Characterized by an increased surface and subsurface porosity, fluorides are causing opacity, pitting or staining of the enamel. At a level of ppm fluoride in domestic water supplies, the prevalence of fluorosis has been estimated to be approximately $51 \%$, but most of the fluorosis is of a very mild nature and the public does not generally notice it. Fluorosis is the first visible sign of an excessive intake of fluoride during the period of enamel formation. A major risk factor in fluorosis is the inappropriate use of fluoride toothpaste in young children who may not be able to expectorate it adequately [31]. 
In addition to water fluoridation with a variation between 0.7 to $1.0 \mathrm{ppm}$, fluoride supplements are given to children living in fluoride-deficient areas. Topical fluoride added to swallowing fluoride-containing toothpastes may also be responsible for dental fluorosis, contributing to mild to severe fluorosis [32].

The lowest dose of fluoride in drinking water that induces visible and lasting defects in fully mature rat incisor enamel is $25-30 \mathrm{ppm}(1.3-1.6 \mathrm{mM})$ fluoride. Injections of moderate doses (3-7 mg F/ kg body weight) affect cell structure of early-secretory ameloblasts and reduce protein synthesis dose-dependently and transiently. A single higher dose of fluoride ( $9 \mathrm{mg} \mathrm{F} / \mathrm{kg}$ body weight) induces cyst formation by early-secretory ameloblasts in the cervical loop area of developing hamster molars, and affects the structure of these ameloblasts. The aprismatic enamel under these cyst-forming layers of early-secretory cells is extremely hypermineralized. In contrast, enamel matrix secreted during fluoride exposure fails to mineralize (referred to as 'fluorotic matrix'). Most severe lesions are pits and grooves in the enamel seen occlusally or cervically. Cervically located deep, narrow, hypoplastic pits have been found in highly fluorotic molars and premolars. The damage to early-secretory ameloblasts is correlated with the amount of mineral deposited in the aprismatic enamel and inversely with the thickness of this enamel present before fluoride was given. The thinner the layer of enamel, the more intensely it is hypermineralized, and the more severely the adjacent ameloblasts are affected.

Systematically administered fluorides at a concentration of $75 \mathrm{ppm}$ increase the surface roughness of developing enamel crystals [33]. The dose-dependent roughening of enamel crystal surfaces in vivo in the rat may be mimicked by the in vitro treatment of rat enamel crystals with neutral $\mathrm{pH}$ fluoride solutions. Enamel crystal surface roughness increased after treatment with increasing fluoride ion concentrations, whether applied in vitro or administered systemically. How these roughened crystals may cause fluorosis-involved impairment of crystal growth due to changes in crystal surface chemistry, and/or incomplete removal of modulating matrix proteins, which are known to delay crystal development. Since fluorosis enamel crystals appear to have a greater binding capacity for the matrix proteins, which would lead to their impaired removal, this explain why a greater concentration of proteins is found, together with an impaired crystal growth in fluorotic enamel. In turn, these results explain the occurrence of hypomineralized enamel.

The effects of fluoride on enamel formation causing dental fluorosis in man are cumulative, depending on the total fluoride intake from all sources and the duration of fluoride exposure. Enamel mineralization is highly sensitive to free fluoride ions, which uniquely promote the hydrolysis of acidic precursors such as octacalcium phosphate and precipitation of fluoridated apatite crystals. Once fluoride is incorporated into enamel crystals, the ion likely affects the subsequent mineralization process by reducing the solubility of the mineral and thereby modulating the ionic composition in the fluid surrounding the mineral.

A single injection with a low ( $2 \mathrm{mg} \mathrm{F} / \mathrm{kg}$ body weight) to high dose of fluoride (14 mg F/ $/ \mathrm{kg}$ body weight) induces a characteristic double-response event in secretory enamel, consisting of an inner hyper-followed by an outer hypomineralized line. Injections given some time apart result in corresponding multiple alternating double-response lines, running in the enamel almost parallel to the enamel surface.

Mild cases of dental fluorosis are characterized by a white opaque appearance of the enamel, caused by increased subsurface porosity. The earliest sign is a change in color, showing many thin white horizontal lines running across the surfaces of the teeth, with white opacities at the newly erupted incisal end. The white lines run along the 'perikymata', a term referring to transverse ridges on the surface of the tooth, which correspond to the incremental lines in the enamel known as Striae of Retzius. With increased dental fluorosis, the entire tooth can be chalky white and lose transparency. Teeth can erupt with pits, with additional pitting occurring with post-eruptive enamel fracture. Yellow to light brown staining is observed in the areas of enamel damage. In very severe cases, the enamel is porous, poorly mineralized, stains brown, and contains relatively less mineral and more proteins than sound enamel.

Millimolar concentrations ( $\mathrm{mM}$ ) of fluoride act as an enzyme inhibitor for a variety of serine proteases, where as sodium fluoride is used as a general inhibitor of protein phosphoseryl and phosphothreonyl phosphatases. Fluoride is mitogenic at low concentrations and toxic at higher concentrations. Sodium fluoride seems to act predominantly through the Jun $\mathrm{N}$-terminal kinase and p38 MAPK signaling pathways. The mechanism(s) underlying DF remain obscure, but likely contribute to the observed retention of enamel matrix proteins and may include reduced removal of enamel matrix proteins during enamel maturation, perturbation of extracellular transport, or initiation of the ER stress-response pathway.

\section{Genetic Studies}

Few studies have explored the underlying genetic basis for fluoride resistance or susceptibility. Among the first, high concentrations of fluoride $(400 \mu \mathrm{g} / \mathrm{mL})$ have been used to isolate fluoride-resistant mutants of Caenorhab- 
ditis elegans. Genetic studies of these mutant nematodes have led to the identification of novel fluoride-resistant (flr) genes. The flr1 gene encodes an ion channel belonging to the degenerin/epithelial sodium channel superfamily. Inbred mouse strains have been used for genetic studies because of the isogenicity within a strain and the genetic heterogeneity between inbred strains. The genetic diversity existing between inbred strains of mice has yielded phenotypes relevant to human health, such as cancer susceptibility, aging, obesity, and susceptibility to infectious diseases, atherosclerosis, blood disorders, and neurosensory disorders. From that study, strains clustered into three dental fluorosis groups: Resistant, intermediate, and sensitive strains.

Resistance and susceptibility (risk factors), defined by host and environment interactions, as well as many quantitative phenotypes are considered as complex traits. These phenotypes can be assessed quantitatively and are under the control of multiple genes as well as non-genetic (environmental) factors. Multiple genes contribute to the variation in a phenotypic trait. They are called Quantitative Trait Loci (QTL). QTLs can be mapped in mice by traditional genetic approaches. Future studies will identify and characterize fluoride-responsive genetic variations (e.g., polymorphisms). They also aimed to identify the human populations at-risk who are susceptible to the unwanted or potentially adverse effects of fluoride action. Finally, they may contribute to elucidate the fundamental mechanisms by which fluoride affects biomineralization [34].

Analyzing enamel defects due to fluorosis in wild type mice and mice deficient in anion exchanger- $2 \mathrm{a}, \mathrm{b}$ (Ae2a,b), a transmembrane protein was found in maturation ameloblasts that exchanges extracellular $\mathrm{Cl}^{-}$for bicarbonate. Defects were more pronounced in fluorotic Ae2a, $\mathrm{b}^{-/-}$mice than in fluorotic heterozygous or wildtype mice. The phenotype includes a hypermineralized surface, extensive subsurface hypomineralization, and multiple hypermineralized lines in deeper enamel. Mineral content decreased in all fluoride exposed and $\mathrm{Ae} 2 \mathrm{a}, \mathrm{b}^{-/-}$mice. It was strongly correlated with $\mathrm{Cl}^{-}$. Fluorotic enamel may impair the diffusion of protons and mineral ions. Fluoride stimulates enamel hypermineralization, which briefly acidifies enamel matrix. Acidification could influence ion transport and modulation. Hypermineralized bands in the enamel may delay the mineralization process by acting as a physical barrier, impairing diffusion of ions and peptides [35].

Excess of fluoride during tooth development causes enamel fluorosis:

a. In mild fluorosis, white opaque striations are seen across the enamel surface. b. In more severe cases, the porous regions increase in size, with enamel pitting and secondary discoloration of the enamel surface.

c. At high fluoride levels, fluoride affects directly ameloblasts, the enamel-forming cells. At low fluoride level, there is a local effect on the mineralizing matrix.

A multi-stage model for the formation of fluorosed enamel, has been proposed: [33-35]

1. Crystals forming in the secretory stage of enamel have an increased fluoride content and therefore bind more amelogenin.

2. Hydrolysis of amelogenins by proteinases is delayed by altered interactions with the fluoride-containing hydroxyapatite crystals.

3. At the transition stage, fluoride is rapidly deposited into the porous enamel matrix between the open cell junctions, resulting in an increased formation of fluoride containing apatite, and a delay in protein hydrolysis and secondary altered mineral/matrix interactions.

4. The fluoride-related effects in the secretory and transition stages are retention of amelogenins in the maturation stage. This delay the removal of amelogenins, increases the relative $\mathrm{pH}$ in the maturation stage under ruffle-ended ameloblasts, taking into account that amelogenins buffer the increased protons resulting from mineral formation.

5. The reduced acidification of the matrix under ruffleended ameloblasts further delays the modulation to smooth-ended ameloblasts.

6. In late maturation, when amelogenins are finally removed (or in mild dental fluorosis with minimal amelogenin retention), fluoride-mediated hypermineralization may increase the local acidification affecting ameloblast function, such as ion transport activities. Although porous subsurface enamel is the major phenotype of fluorosed enamel, successive layers of hypo- and hypermineralized enamel are also characteristic of the fluorosed enamel matrix.

\section{Fluorosis Index of H.T. Dean (1938) [36]}

\begin{tabular}{|l|l|}
\hline Score & Criteria \\
\hline Normal (0) & $\begin{array}{l}\text { Enamel represents the usual translucent } \\
\text { semi vitriform type of structure. The sur- } \\
\text { face is smooth, glossy, and usually of a } \\
\text { pale creamy white color. }\end{array}$ \\
\hline Questionable (0.5) & $\begin{array}{l}\text { The enamel discloses slight aberrations } \\
\text { from the translucency of normal enamel, } \\
\text { ranging from a few white flecks to occa- } \\
\text { sional white spots. This classification is } \\
\text { utilized in those instances where a definite } \\
\text { diagnosis of the mildest form of fluorosis is } \\
\text { not warranted and a classification of 'nor- } \\
\text { mal' is not justified. }\end{array}$ \\
\hline
\end{tabular}




\begin{tabular}{|l|l|}
\hline Very mild (1) & $\begin{array}{l}\text { Small opaque, paper white areas scatte- } \\
\text { red irregularly over the tooth but not invol- } \\
\text { ving as much as } 25 \% \text { of the tooth surface. }\end{array}$ \\
$\begin{array}{l}\text { Frequently included in this classification } \\
\text { are teeth showing no more than about 1-2 } \\
\text { mm of white opacity at the tip of the sum- } \\
\text { mit of the cusps of the bicuspids or second } \\
\text { molars. }\end{array}$ \\
\hline Mild (2) & $\begin{array}{l}\text { White opaque areas in the enamel of the } \\
\text { teeth are more extensive but do not invol- } \\
\text { ve as much as 50\% of the tooth. }\end{array}$ \\
\hline Moderate (3) & $\begin{array}{l}\text { All enamel surfaces of the teeth are affec- } \\
\text { ted, and the surfaces subject to attrition } \\
\text { show wear. Brown stain is frequently a } \\
\text { disfiguring feature. }\end{array}$ \\
\hline Includes teeth formerly classified as 'mo- \\
derately severe and severe'. All enamel \\
surfaces are affected and hypoplasia is so \\
marked that the general form of the tooth \\
may be affected. The major diagnostic \\
sign of this classification is discrete or con- \\
fluent pitting. Brown stains are widespread \\
and teeth often present a corroded-like \\
appearance.
\end{tabular}

\section{Secretory ameloblasts}

These are relatively resistant to the effects of acute fluoride exposure in comparison with early- and late secretory cells. Cellular changes in secretory ameloblasts in vivo are reported only after the injection of high levels of fluoride. One or multiple injections of moderate (4-9 $\mathrm{mg} \mathrm{F} / \mathrm{kg}$ bodyweight) doses of fluoride into adult rats can transiently disrupt the structure of secretory ameloblasts in incisors, causing accumulation of matrix proteins, generating clear vacuoles, decreasing deposition of matrix, and inducing the typical double-response of hypermineralized followed by hypomineralized lines or bands in secretory enamel. Double-response lines and disturbances in mineralization patterns are apparent in secretory enamel after a single injection of $2.2-9 \mathrm{mg} \mathrm{F} / \mathrm{kg}$ body weight, but without significant structural changes in fully secretory ameloblasts $24 \mathrm{hrs}$ after injection. Chronic exposure to fluoride in drinking water or repeated injections of moderate fluoride doses reduces the thickness of enamel by about $10 \%$.

\section{Maturation ameloblasts}

Although maturation-stage enamel seems to be most sensitive to fluoride, there are remarkably few structural changes in the maturation ameloblasts exposed to fluoride. No major structural changes have been found in maturation ameloblasts of molar tooth germs of rodent pups shortly after injection of a single high dose of fluoride that severely damages early- and late-secretory ameloblasts seen in the same teeth. The maturation stage of enamel development can be affected by fluoride, even if there is no fluoride exposure in earlier stages, and is considered the stage most susceptible to fluoride exposure.
The outer surface of the enamel progressively is hypermineralized during the maturation stage under chronic fluoride exposure. Crystals in sound enamel are extremely long, and the dynamics of enamel crystal growth, sizes of the crystals, and their shape are well controlled by matrix proteins during enamel formation. Fluoride causes mineralization defects and decreases enamel hardness. This suggests that fluoride may change the size, number, and shape of the crystals, or their quality by interfering with their formation.

There is not much detailed information available on enamel crystals in mature human fluorotic enamel. The few published studies disagree with each other with respect to the dimensions and morphology of fluorotic crystals. Major effects of chronic fluoride intake are induced during the maturation stage, resulting in a hypomineralized subsurface enamel that contains less mineral and retains matrix. Many studies have proposed that fluoride impairs the degradation of matrix proteins, with a resultant inhibition of crystal growth. Fluoride reduces degradation of ECM by lowering the output of proteases by the ameloblasts. Fluoride inhibits matrix degradation, change the adsorption characteristics, and the surface properties of enamel crystals. Fluoride impairs endocytosis and intracellular degradation. Finally, fluoride increases apoptosis [37-41].

Prescription of dietary fluoride contributes to caries prevention. Two known classifications of effects in controlling dental caries were reported: Topical and systemic. When fluoride supplements are prescribed, what is the dosage schedule for dietary fluoride supplement?

a. When absorbed by enamel crystals during the remineralization process, the crystal structure is improved, becoming more acid resistant, contains more fluoride and less carbonate. Fluoride inhibits the carbohydrate metabolism and acid production. The production of adhesive polysaccharides by bacteria is affected. The optimum concentration for fluoride in the water is in the range of 0.7 to $1.2 \mathrm{ppm}$ to reduce dental caries while minimizing dental fluorosis. To conclude on this point, enamel fluorosis seems to be important in the prevention and control of dental caries.

b. Fluoride intake may induce a surface (sub-surface) hypomineralization if the intake occurs during tooth development early in life. Variations may occur also between minor striations and larger areas of affected enamel. The severity and distribution of enamel fluorosis depends on the amount, duration, and timing of fluoride intake. Enamel fluorosis is either mild, very mild, or going from moderate to severe.

The clinical recommendations for the use of dietary fluoride supplement are the following: 
Citation: Goldberg M (2018) Fluoride: Double-Edged Sword Implicated in Caries Prevention and in Fluorosis. J Cell Dev Biol 1(1):10-22

From birth to 6 months: No supplementation

From 6 months to 3 years: $0.25 \mathrm{ppm} /$ day

From 3 to 6 years: $0.50 \mathrm{ppm} /$ day

From 6 to 16 years: $1.00 \mathrm{ppm} /$ day

\section{Conclusion}

On the one hand, both in primary and permanent teeth the incidence of caries can be reduced by dietary fluoride supplements. On the other hand, the fluoride intake during tooth development contributes to the risk of enamel fluorosis. There is a need for assessment and judicious prescription of dietary fluoride supplement, with consideration of total fluoride intake.

The cariostatique mechanisms of fluoride contribute to demineralization and remineralization of dental hard tissues. The sources may be either (1) Fluoroapatite due to the incorporation of fluoride into enamel, or (2) Calcium fluoride ( $\mathrm{CaF}$ )-like precipitates, formed on the enamel and in the plaque after application of topical fluoride. A phosphate-protein coating of salivary origin protects these deposits. Presumably, $\mathrm{CaF}_{2}$ has a direct and indirect effect on bacterial cells [42].

\section{References}

1. Trautz OR Cristalline (1967) Organization of dental mineral. In: AEW Miles, Structural and chemical organization of teeth. Academic Press New York, USA, 165-200.

2. Montel G (1975) Conceptions actuelles sur la structure et la constitution des apatites synthétiques comparables aux apatites biologiques: Colloques Internationaux CNRS. No 230-Physicochimie et cristallographie des apatites d'intéret biologique 13-18.

3. Aoba $T$ (1997) The effect of fluoride on apatite structure and growth. Crit Rev Oral Biol Med 8: 136-153.

4. Elliott JC (1997) Structure, crystal chemistry and density of enamel apatites. Ciba Found Symp 205: 54-67.

5. Mathew M, Takagi S (2001) Structures of biological minerals in dental research. J Res Natl Inst Stand Technol 106: 1035-1044.

6. Leroy N, Bres E (2001) Structure and substitutions in fluorapatite. Eur Cells Mater 2: 36-48.

7. Okazaki M (1992) Heterogeneous synthesis of fluoridated hydroxyapatites. Biomaterials 13: 749-754.

8. Larsen MJ (1990) Chemical events during tooth dissolution. J Dent Res 69: 575-580.

9. Ten Cate JM, Featherstone JD (1991) Mechanistic aspects of the interactions between fluoride and dental enamel. Crit Rev Oral Biol Med 2: 283-296.

10. Rosin Gret K, Peros K, Sutej I, et al. (2013) The cariostatic mechanisms of fluoride. Acta Med Acad 42: 179-188.

11. Beevers CA, McIntyre DB (1964) The atomic structure of fluorapatite and its relation to that of tooth and bone material. Miner Mag 27: 254-257.

12. Kay MI, Young RA, Posner AS (1964) Crystal structure of hydroxyapatite. Nature 204: 1050-1052.

13. Featherstone JD (2008) Dental caries: A dynamic disease process. Aust Dent J 53: 286-291.

14. Fan Y, Sun Z, Moradian-Oldak J (2009) Controlled remineralization of enamel in the presence of amelogenin and fluoride. Biomaterials 30: 478-483.

15. Gonzalez-Cabezas C (2010) The chemistry of caries: Remineralization and demineralization events with direct clinical relevance. Dent Clin North Am 54: 469-478.

16. Anusavice KJ (2005) Present and future approaches for the control of caries. J Dent Educ 69: 538-554.

17. Reynolds EC (2008) Calcium phosphate-based remineralization systems: Scientific evidence? Aust Dent J 53: 268273.

18. Twetman S, Axelsson S, Dahlgren H, et al. (2003) Caries-preventive effect of fluoride toothpaste: A systematic review. Acta Odontol Scand 61: 347-355.

19. Thylstrup A (1990) Clinical evidence of the role of pre-eruptive fluoride in caries prevention. J Dent Res 69: 742-750.

20. Ingram GS, Agalamanyi EA, Higham SM (2005) Caries and fluoride processes. J Dent 33: 187-191.

21. Arends J, Jongebloed WL (1979) Ultrastructural studies of synthetic apatite crystals. J Dent Res 58: 837-843.

22. Featherstone JD (2000) The science and practice of caries prevention. J Am Dent Assoc 131: 887-899.

23. Margolis HC, Moreno EC, Murphy BJ (1986) Effect of low levels of fluoride in solution on enamel demineralization in vitro. J Dent Res 65: 23-29.

24. Fejerskov O, Thylstrup A, Larsen MJ (1981) Rational use of fluorides in caries prevention: A concept based on possible cariostatic mechanisms. Acta Odontol Scand 39: 241-249.

25. Wong MC, Clarkson J, Glenny AM, et al. (2011) Cochrane review on the benefits/risks of fluoride toothpastes. J Dent Res 90: 573-579.

26. Gussy MG, Waters E, Walsh O, et al. (2006) Early childhood caries: Current evidence for aetiology and prevention. J Paediatr Child Health 42: 37-43.

27. Kawashita Y, Kitamura M, Saito T (2011) Early childhood caries. International Journal of Dentistry 2011: 725320.

28. Griffin SO, Regnier E, Griffin PM, et al. (2007) Effectiveness of fluoride in preventing caries in adults. J Dent Res 86: 410-415.

29. Bansal A, Ingle NA, Kaur N, et al. (2015) Recent advancements in fluoride: A systematic review. J Int Soc Prev Community Dent 5: 341-346.

30. Newbrun E (2001) Topical fluorides in caries prevention and management: A North American perspective. J Dent Educ 65: 1078-1083.

31. Pizzo G, Piscopo MR, Pizzo I, et al. (2007) Community water fluoridation and caries prevention: A critical review. Clin Oral Investig 11: 189-193.

32. Abanto Alvarez J, Rezende KM, Marocho SM, et al. (2009) Dental fluorosis: Exposure, prevention and management. Med Oral Patol Oral Cir Bucal 14: E103-E107.

33. Chen H, Czajka Jakubbowska A, Spencer NJ, et al. (2006) 
Effects of systemic fluoride and in vitro fluoride treatment on enamel crystals. J Dent Res 85: 1042-1045.

34. Everett ET (2011) Fluoride's effects on the formation of teeth and bones, and the influence of genetics. J Dent Res 90: $552-560$.

35. Lyaruu DM, Medina JF, Sarvide S, et al. (2014) Barrier formation: Potential molecular mechanism of enamel fluorosis. J Dent Res 93: 96-102.

36. Dean HT (2006) Endemic fluorosis and its relation to dental caries. 1938. Public Health Rep 121: 213-219.

37. Bronkers AL, Lyaruu DM, DenBesten PK (2009) The impact of fluoride on ameloblasts and the mechanisms of enamel fluorosis. J Dent Res 88: 877-893.

38. Denbesten P, Li W (2011) Chronic fluoride toxicity: Dental fluorosis. Monogr Oral Sci 22: 81-96.
39. Lussi A, Hellwig E, Klimek J (2012) Fluorides - mode of action and recommendations for use. Schweiz Monatsschr Zahnmed 122: 1030-1042.

40. Hicks J, Garcia-Godoy F, Flaitz C (2004) Biological factors in dental caries: Role of remineralization and fluoride in the dynamic process of demineralization and remineralization (part 3). J Clin Pediatr Dent 28: 203-214.

41. Aoba T, Fejerskov O (2002) Dental fluorosis: Chemistry and biology. Crit Rev Oral Biol Med 13: 155-170.

42. Rozier RG, Adair S, Graham F, et al. (2010) Evidence-based clinical recommendations on the prescription of dietary fluoride supplements for caries prevention: A report of the American Dental Association Council on Scientific Affairs. J Am Dent Assoc 141: 1480-1489. 